\title{
The Usage of The Ucla Scale in the Life Quality of the Impingement: Case Study
}

\author{
Matheus De Siqueira Mendes Barbalho ${ }^{1}$, Paulo Henrique Lima Rodrigues², \\ Fernando Thiago Frazão ${ }^{2}$, Ronivaldo Da Silva Pires ${ }^{2}$ \\ ${ }^{1}$ Center For Biological And Health Sciences, Faculty Of Physiotherapy And Physical Education, University Of \\ Amazônia, Brazil \\ ${ }^{2}$ Center For Biological And Health Sciences, Faculty Of Physiotherapy, University Of Amazônia, Brazil.
}

\begin{abstract}
The shoulder frequently has complaints in orthopedic practice, due to its wide range of motion and mechanical stresses of daily activities, one of the most common injuries is the impingement. The work aims to use the UCLA scale evaluation of impingement syndrome and then relate to the ICF. The scale analyzes five parameters: pain, function, ADM, manual strength and patient's satisfaction, and so we will relate their usefulness in the analysis of the codes, relating to ICF. This is a case study, descriptive and quantitative, performed at the Clinical School Fisioclinica from Universidade da Amazonia (UNAMA) in Belém / PA. A female patient participated in the study, a 62 years old housewife, diagnosed with the impingement syndrome on her left shoulder. A standard traumatology and orthopedics form from the clinic was used, containing anamnesis, physical exams and specific tests. The combination of results obtained from the patient, with the functional scale and the ICF, analyzes that since the patient presented, besides functional alterations - that prevents her from doing her daily-live activities, pain, resulting in a 10 points score, in the UCLA scale, considered bad, being related to the codes b2801, b289, b789 b7100, b7200 and b7300, which present pain, loss of function, mobility and muscular strength. So, we can conclude that the UCLA scale allows to perform the evaluation of the SIO and its correlation with the ICF scale may be done through the levels that the ICF generates, which are the codes that link with the symptoms evaluated by the scale and that the patient with SIO shows.
\end{abstract}

Keywords: Functionality, ICF, UCLA.

\section{Introduction}

Shoulder's alterations, usually, are very frequent complaints in the orthopedic practice, given its great articular amplitude of movement and its mechanical needs from the daily and sportive activities, and by that the glenohumeral and the scapular humeral articulations show many painful incidences and instabilities. These articular instabilities, mostly from traumatic origin, go along with articular space loss, causing impacts over the tendons that cover the humeral head, and because of this, one of the most common lesions is the impingement, described by Neer in 1972[1].

The shoulder impingement (SI) is a pathology that occurs by the compression of structures that are located in the sub acromial space, as the rotator cuff, the biceps' long headed tendon and the sub acromial bursa. During the elevation of the upper limb, these structures are submitted to micro traumas of repetition, between the humerus' biggest tubercle and the coracoacrimal arc. Through these micro traumas, it may result in an inflammation of the soft tissues, making them edematous, bringing a decrease of the sub acromial space [2].

The causes for this disease may come from intrinsic factors, resulting from the physiologic alteration of the sub acromial space structures, which include muscular weakness and excessive use, besides the extrinsic factors that are related to the mechanical impact of the coracoacrimal arc structures, such as the sub acromial impact, glenohumeral instability, impact with the coracoid and/or the acromion process and the impact with the glenoid's poster-superior area [3].

According to Dutton (2004) [4], the impingement in constituted in an arrangement of varied alterations that may occur by pain and functional limitation, mostly in activities performed over 90 degrees, and one of the most common causes of the impingement are tendinitis of the rotator cuff's muscles that if aren't treated in time can evolve to a complete rupture of the tendons.

The acromion type has influence on the impingement, existing three anatomic types: type I (straight), type II (curved) and type III (in a hook way), and some authors [5] write that the third type consists in an anatomic variation that comes from bone calcifications created along time; So, it is concluded that the bigger the curve, more serious the chance of developing the impingement [6].

The diagnosis is started in the clinical evaluation of the patient through anamneses, physical exams, special tests that are used for diagnosis and may be complemented through image exams, such as the magnetic resonance, conventional radiography [7].

DOI: 10.9790/1959-0504018589 $\quad$ www.iosrjournals.org $\quad 85 \mid$ Page


The physiotherapy has an important role in the impingement's rehabilitation, helping in the recovery of the patient's upper limb that suffers, helping him to do better his daily activities, eliminating the painful and inflammatory picture, besides helping in the prevention, avoiding relapses of the disease, and also aiding the patient to not need possible surgeries [7].

In the literature, authors such as Neer [1], Amstutz [8], Rowe [9] and Ellman [10] present protocols, tests and scales that aim to create a pattern for the initial evaluation and the accomplished results. These scales have specific characteristics for determined alterations; they are practical and of easy application, accomplishing its results in an objective way. Among the evaluation methods in the literature, this study chose the University of California at Los Angeles' (UCLA) test.

\section{Case report description}

It's about a case study, descriptive and quantitative [11]. Performed at the Clinical School Fisioclínica from Universidade da Amazonia (UNAMA) in Belém / PA. For the fulfillment of the research, the principles contained in the 446/12 from the Brazilian National Health Board (CNS) were followed, which regulates the researches involving human beings [12]. The selected patient has read and signed the Term of Free and Clear Consensus (TFCC).

Participated in the study the patient M. C. L. M., female, 61 years old, black, married, housewife, sent to the Fisioclinica complaining about numbness and lack of muscular strength and movement amplitude (ADM) in the left upper limb, in the shoulder's area, diagnosed by a doctor as with impingement in the left shoulder. According to what was said, the picture began in 2005, after she was victim of a robbery, in which she suffered physical aggression, hurting the left shoulder, after this incident the patient reports pain while using the mass transit services, because she always stays with the arm in a flexion position above her head, by the end of the day the arm shows paresthesia and pains in the shoulder, since the first episode reported and because of her daily routine, the patient reports constant pains in the shoulder and difficulties in her daily activities.

It was used in this research the standard evaluation file of traumatic-orthopedic of the Clinical School Fisioclinica, containing anamneses, physical exams and specific tests: Appley, Neer, Jobe and Speed, in which were used the following equipment: neurologic hammer, goniometer, one tape measure, stethoscope, sphygmomanometer for the Arterial Pressure (AP) verification and the UCLA scale.

The UCLA questionnaire was developed by the University of California - Los Angeles, originally to evaluate the results of the shoulder arthroplasty8. The questionnaire was adopted later by Ellman [10], to evaluate rotator cuff lesions, in which were inserted evaluations from ADM, muscular strength and patient's satisfaction in its criteria for the final score. The questionnaire evaluates subjectively the pain and the function. For the pain reported as strong, needing analgesics usage frequently it receives 1 point, if there isn't pain: 10 points, in the case of the patient in this study, who is always showing pain, bearable and sometimes uses strong analgesics, 2 points were assigned. About the function, its score goes from 1 to 10, one point is assigned when the patient is incapable of using the member and ten when the subject can do its daily activities normally, in case of this patient, 2 points were assigned, because she can perform only a few light activities.

In ADM and strength, we evaluated only the active flexion, scoring 5 points tops for flexions over $150^{\circ}$ and with 0 these below $30^{\circ}$. The patient received 3 points, performing the active flexion from $90^{\circ}$ to $120^{\circ}$. The muscular strength is tested manually graduating from 0 to 5 , being given 0 when there's no strength and 5 when there is normal strength. For the patient, it was given 3 points, a regular level. The satisfaction of the patient is scored in 5 for satisfied and 0 for unsatisfied, the patient reported in the evaluation 0 , for unsatisfied.

The total number of possible points is 35, classifying the results in excellent for scores between 34 and 35 , good between 28 and 33, regular from 21 to 27 and bad from 0 to 20. The patient's final sum was of 10 points, fitting in the bad result, presented in table 1 . 


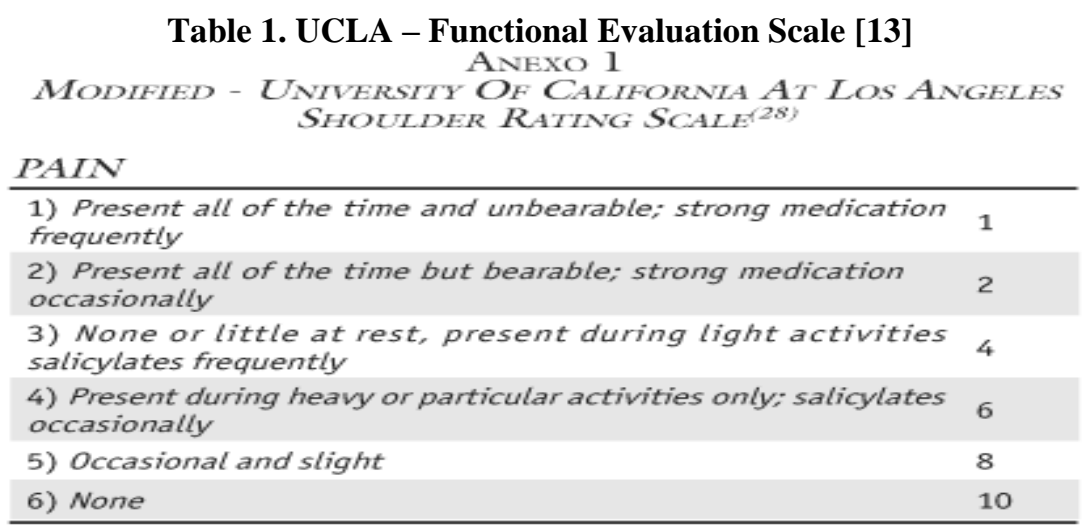

\begin{tabular}{lc} 
FUNCTION & \\
\hline 1) Unable to use limb & 1 \\
2) Only light activities possible & 2 \\
3) Able to do light housework or most activities of daily living & 4 \\
$\begin{array}{l}\text { 4) Most housework, shopping, and driving possible; able to do hair } \\
\text { and dress and undress, including fastening brassiere }\end{array}$ & 6 \\
5) Slight restriction only; able to work above & \\
shoulder level & 8 \\
6) Normal activities & 10 \\
\hline
\end{tabular}

\section{ACTIVE FORWARD FLEXION}

\begin{tabular}{ll}
\hline 1) 150 degrees or more & 5 \\
2) 120 to 150 degrees & 4 \\
3) 90 to 120 degrees & 3 \\
4) 45 to 90 degrees & 2 \\
5) 30 to 45 degrees & 1 \\
6) Less than 30 degrees & 0 \\
\hline
\end{tabular}

STRENGTH OF FORWNARD FLEXION ( $M A N U A L$ MUSCLE-TESTING)

\begin{tabular}{ll}
\hline 1) Grade 5 (normal) & 5 \\
2) Grade 4 (good) & 4 \\
3) Grade 3 (fair) & 3 \\
4) Grade 2 (poor) & 2 \\
4) Grade 1 (muscle contraction) & 1 \\
6) Grade o (nothing) & 0 \\
\hline & \\
\hline 1) Satisfied and better & 5 \\
2) Not satisfied and worse & 0 \\
\hline
\end{tabular}

In the presented study, the UCLA usage was a way to evaluate the pain, function, movement amplitude and shoulder strength, the same may be used to analyze data found pre and post physiotherapeutic intervention, being able to measure significant results after the intervention. The UCLA scale is extremely used in postsurgeries of lesions of the rotator scuff and of Bankart, given its efficacy in the functional aspect, being an analysis instrument alongside with the complementary exams and other scales, such as the visual analogic scake, for the post-surgery perception, being the patient indicated to physiotherapy[14], [15].

Evaluation data from the orthopedic tests complement the diagnosis and analysis of the scale, the trials from Apley, Jobe and Neer, turned positive, the first two showing lesion of the tendons of the cuff, being Jobe's the most specific for supra-spine and Neer's test, specific for impingement, pathology that was observed in the patient. The only test that turned negative was Speed's, to evaluate the tendon of the arm-biceps. In goniometry and perimetry, differences were shown between the two segments, while in the lesioned left arm the patient showed $110^{\circ}$ in shoulder's abduction, the right showed complete amplitude, in the supra-olecranon perimetry the left arm showed one $2 \mathrm{~cm}$ distance deficit, in the 10,15 and $20 \mathrm{~cm}$ measures, in comparison with the right arm. 
With the obtained result of ten points in the scale, we may conclude that the same is fit for many levels that the CIF describes. Such as, movement function alterations, organs, skin, and others. The classifications associated with what was shown by the patient after evaluation submitted with the scale were: b2801, b289, b789, b7100, b7200 and b7300, presented in table 2 .

The following classification according to the CIF level, code b289, pain sensation, other specified and non-specified, and b2801 pain located and unpleasant sensation felt in one or more parts of the body, what indicates potential or real lesion of any structure of the body is justified by the factor, painful picture, presented by the patient during the performed evaluation, applying the functional scale.

Besides this, too, the b789, that focuses on the movement functions, other specified and non-specified. It was analyzed this level of the CIF because the patient presents difficulty in performing movements over her head or to get objects in that height. That is fit in what's being showed by this CIF level.

As the CIF approaches more specific branches, this work is also found in the branch. The CIF specific level for the shoulder describes the code, b7200, which presents mobility of the shoulder and functions related to the amplitude and the easiness of the shoulder's movement that include: deficiency such as protraction, retraction, lateral rotation and medial shoulder's rotation.

Table 2. CIF

\begin{tabular}{|c|c|}
\hline CIF's CODE & SIGNS AND SYMPTONS: FUNCTION, MUSCULAR STRENGHT AND \\
PAIN
\end{tabular}

\section{Discussion}

Putting together the patient's results with the functional scale and the CIF, we could analyze that, knowing the fact that the patient presents, besides functional alterations - that limited her movement and prevented her from performing her every day activities - also the patient presents pain symptoms. This became clear after the score that was obtained in the functional scale applied that doesn't evaluate only function, but also pain symptoms, strength and ADM.

The UCLA scale, by the fact that evaluates besides function other items such as ADM and strength, in the scale's application, these items were verified, evaluating only the active flexion, the patient received 3 points out of 5, as already said. Linked to this factor that is the ADM with difficulty of mobility of the articulation, we can quote the b7100 code, that describes the mobility of a single articulation, functions related to the amplitude and easiness of movement from one articulation. And also the code b7300, which describes the strength of the isolated muscles and muscle groups, functions related to the strength created by the contraction of specific muscles and isolated and muscle groups. In the study presented by Mendonça, it is discussed that some shoulder disturbs are influenced by biomechanical factors, according to the performed work, such as in the cases of excessive weight on the upper limbs, vibrations and flexion with arms abduction through long periods of time [16]. It may be associated to the code b7300.

The impingement is the most common disease in the scapular waist, being able to attack both sides being most common in individuals that age between 40 and 50 years [16]. The excessive use of the upper limb with flexion or abduction predisposes the impact, becoming evident the possibility of the disease in the patient, who, because of her occupation, uses a lot the upper limbs. Another important aspect for the incidence of this pathology is its relation to some work activities, being more common in workers that use the upper limbs elevated for long periods of time, case reported by the patient through her use of the mass transit transportation, in which she stays with her arms up to hold herself.

\section{Conclusion}

We may conclude that in this study, the UCLA scale allows the performance of the impingement evaluation, and its correlation to the CIF may be done through the levels that the CIF generates, which are codes that may be associated to symptoms evaluated by the scale, such as pain, function and movement that the patient with impingement shows. 


\section{References}

[1]. Neer II CS. Anterior Acromiplasty for the Chronic Impingement Syndrome in the Shoulder. J Bone Joint Surg Am. 1972; 54$\mathrm{A}(1): 41-50$

[2]. Whiting WC, Zernicke RF. Biomecânica da lesão musculoesquelética. Rio de Janeiro: Guanabara Koogan, 2004.

[3]. Malone TR, Mc Poil TG. Fisioterapia em ortopedia e medicina do esporte. 3. ed. São Paulo: Santos, 2000.

[4]. Dutton M. Fisioterapia ortopédica: Exame, avaliação e intervenção. São Paulo: Artmed, 2004.

[5]. Ikemoto RY, Bezerra AD, Monte FA, Telles RB, Fujiki EM, Porto LCK. Acrômio em forma de gancho: uma variação anatômica ou um processo degenerativo?. Revista Brasileira de Ortopedia, Rio de Janeiro, v.40, p. 454-463, out. 2005.

[6]. Andrade RP, Correa Filho MR, Queiroz BC. Lesões do manguito rotador. Revista Brasileira de Ortopedia, Rio de Janeiro, v.39, p. 621-636 nov./dez. 2004.

[7]. Hebert SK, Barros Filho TEP, Xavier R, Pardini Jr G. Ortopedia e traumatologia: Princípios e pratica. 4 ed. Porto Alegre: Artmed, 2009.

[8]. Amstutz HC, Sew Hoy AL, Clarke IC. UCLA anatomic total shoulder arthroplasty. Clin Orthop 1981:155:7-20.

[9]. Rowe C, Patel D, Southmayd WW. The Bankart procedure: a long-term end-result study. J Bone Joint Surg Am. 1978; 60-A(1):116.

[10]. Ellman H, Gregory H, Bayer M. Repair of the Rotator Cuff. End-result study of factors influencing reconstruction. J Bone Joint Surg Am. 1986; 68-A(8): 1136-44.

[11]. Figueiredo NMA. Método e Metodologia na Pesquisa Científica. 3. ed. São Caetano do Sul: Yendis; 2009.

[12]. Brasil. Ministério da Saúde. Conselho Nacional de Saúde. Normas de pesquisa envolvendo seres humanos. Res. CNS $466 / 96$. Bioética 2012.

[13]. Oku EC, Andrade AP, Stadiniky SP, Carrera EF, Tellini GG. Translation and cultural adaptation of the modified-scale to Portuguese language. Revista Bras Reumatol. Vol 46, n.4, july/aug, 2006.

[14]. Osti L, Buono AD, Maffuilli N. Microfractures at the rotator cuff footprint: a randomized controlled study. International Orthopaedics (SICOT). 37:2165-2171, 2013.

[15]. Li A, Chen Y, Huang G, Huang T. Curative effect of arthroscopic suture anchor fixation on shoulder bankart injury. J Cent South Univ (Med Sci) 2013 Mar;38(3):268-73.

[16]. Mendonça Jr HP, Assunção AA. Associação entre distúrbios do ombro e trabalho: breve revisão da literatura. Rev Bras Epidemiol. 2005;8(2):167-76 